\title{
Mechanisms of Pulmonary Gas Exchange Abnormalities during Experimental Group B Streptococcal Infusion
}

\author{
GREGORY K. SORENSEN, GREGORY J. REDDING, AND WILLIAM E. TRUOG \\ Division of Neonatal and Respiratory Diseases, Department of Pediatrics RD-20, University of Washington \\ School of Medicine, Seattle, Washington 98195
}

\begin{abstract}
Group B streptococcal sepsis in newborns produces pulmonary arterial hypertension and hypoxemia. The purpose of this study was to investigate the mechanisms by which hypoxemia occurs. Ten anesthetized, ventilated piglets were infused with $2 \times 10^{9}$ colony forming units $/ \mathrm{kg}$ of Group B streptococci over a 30 -min period. Pulmonary arterial pressure rose from $14 \pm 2.8$ to $38 \pm$ 6.7 torr after $20 \mathrm{~min}$ of the bacterial infusion $(p<0.01)$. During the same period, cardiac output fell from 295 to $184 \mathrm{ml} / \mathrm{kg} / \mathrm{min}(p<0.02)$. Arterial $\mathrm{PO}_{2}$ declined from 97 \pm 7 to $56 \pm 11$ torr $(p<0.02)$ and mixed venous $\mathrm{Po}_{2}$ fell from $39.6 \pm 5$ to $28 \pm 8$ torr $(p<0.05)$. The multiple inert gas elimination technique was used to detect increases in shunt and alterations in ventilation-perfusion matching. Intrapulmonary shunt did not increase during or after the infusion with group B streptococci. However, there was a significant increase $(p<0.05)$ in the SD of pulmonary blood flow, an index of $\dot{V}_{A} / \dot{Q}$ mismatching, 20 min after initiation of the infusion of bacteria. All the above changes reverted toward baseline during the 2 -h period following discontinuation of the infusion. We conclude that the hypoxemia occurring in the early phase of group B streptococcal sepsis does not develop solely because of increased shunt, but rather is produced by a decline in cardiac output in conjunction with mismatching of pulmonary perfusion to alveolar ventilation. (Pediatr Res 19: 922-926, 1985)
\end{abstract}

\section{Abbreviations}

GBS, Group B streptococcal

Ppa, pulmonary arterial pressure

PVR, pulmonary vascular resistance

Qp, pulmonary blood flow

$V_{A} / Q$, ventilation-perfusion ratio

$\mathrm{P}_{v} \mathrm{O}_{2}$, mixed venous $\mathrm{PO}_{2}$

Neonatal GBS infection produces septicemia, shock, and arterial hypoxemia (1). While the constellation of clinical findings, risk factors, and incidence rate of early onset GBS sepsis have been previously reported $(2,3)$, the pathophysiologic events producing arterial hypoxemia have not been well studied. Pulmonary hypertension has been reported in an adult experimental model infused with live GBS (4) or with polysacchride toxin

Received February 19. 1985: accepted April 24, 1985

Reprints William E. Truog. M.D. Associate Professor of Pediatrics, Division of Neonatal and Respiratory Diseases. University of Washington School of Medicine. Seattle, WA 98195

Supported in part by NIH HL01205 RCDA (W.E.T.). NIH HL19187 (Pediatric Pulmonry SCOR), and a grant from the Washington Lung Association (G.J.R.). obtained from $\mathrm{GBS}(5,6)$. Arterial $\mathrm{PO}_{2}$ fell by 9 torr in association with the increase in pulmonary arterial pressure (4). In contrast, the neonatal piglet infused with GBS demonstrated both pulmonary arterial hypertension and profound arterial hypoxemia (7). These results suggest that the neonatal pulmonary vasculature may respond to bacteremia differently from that of adults.

The relationship between Ppa and the matching of alveolar ventilation and pulmonary perfusion, a major determinant of arterial oxygenation during room air breathing (8), has not been studied in newborns. The predictable rise in Ppa with an infusion of group B streptococcus offers an opportunity to delineate the relationship between pulmonary gas exchange and pulmonary hemodynamics and to understand the cause of hypoxemia during sepsis in the neonate. Newborn animals are likely to have some degree of intrapulmonary shunt (9). A rise in Ppa and PVR might increase shunt, if the rise in PVR is produced by constriction of relaxed pulmonary vessels located within well-ventilated regions of the lung (10), rather than by vessels that are constricted in regions of alveolar hypoxia. The altered relationship between resistance to flow in shunt and nonshunt associated areas would result in increased flow to shunt vessels.

This study tested the hypothesis that arterial hypoxemia associated with the acute rise in Ppa during the early stages of GBS sepsis in newborns is caused primarily by an increase in intrapulmonary shunt.

\section{MATERIALS AND METHODS}

Animal preparation and monitoring. Ten piglets, age 10-20 days and mean weight $3.2 \mathrm{~kg}$ (weight range $2.6-4.2 \mathrm{~kg}$ ) were anesthetized with intravenous pentobarbital $(25 \mathrm{mg} / \mathrm{kg})$ and studied in the supine position. Supplemental doses of pentobarbital $(5 \mathrm{mg} / \mathrm{kg})$ were administered hourly to maintain anesthesia throughout the study. Core temperature, measured with a rectal temperature probe, was maintained at $38 \pm 0.5^{\circ} \mathrm{C}$ with a radiant warmer. A triple lumen catheter was placed into the right atrium via the left external jugular vein and a no. 5 Fr. balloon-tipped thermodilution catheter (Edwards Laboratories, Santa Ana, CA) was introduced into the right external jugular vein and positioned under fluoroscopy in the left branch pulmonary artery for measurement of pulmonary arterial and capillary wedge pressures and blood sampling. A polyethylene catheter (PE-160) was introduced into the right internal carotid artery for systemic arterial blood sampling and monitoring blood pressure and heart rate. A metal tracheostomy tube was inserted, secured, and connected to a nonrebreathing valve (11) and a heated 2.5 liter mixed expired gas collection chamber. Tidal volume and minute ventilation were measured with a hot-wire anemometer inserted into the end of the gas collection chamber (12). The anemometer was calibrated before each sampling period over the tidal volume range of $20-40 \mathrm{ml}$, in $5-\mathrm{ml}$ increments, with a signal variation 
of $<2.0 \%$. Mean and phasic pressures were recorded from the aorta, pulmonary artery, and trachea on a four channel polygraph recorder (Hewlett-Packard, Waltham, MA). Signals were averaged electronically.

$\dot{Q}_{p}$ was determined in triplicate using the thermodilution technique (Edwards Laboratories) (13). Values were averaged to obtain the recorded $\dot{Q}_{p}$. If a $>10 \%$ discrepancy among the three values was recorded, a fourth value was also obtained. PVR was calculated from the formula:

$$
\mathrm{PVR}=\mathrm{Ppa}-\mathrm{Ppcwp} / \dot{\mathrm{Q}}_{\mathrm{p}}
$$

where Pcwp is pulmonary capillary wedge pressure.

Following instrumentation, animals were paralyzed with pancuronium bromide $(0.3 \mathrm{mg} / \mathrm{kg})$. Supplemental doses of pancuronium bromide were administered hourly to maintain paralysis. The animals were ventilated with room air using a tidal volume of $15 \mathrm{ml} / \mathrm{kg}$ with a large animal volume ventilator (Harvard Apparatus, Millis, MA). Positive end expiratory pressure was not used. Hyperinflations were delivered $15 \mathrm{~min}$ prior to each sampling period to inhibit development of atelectasis. The respiratory rate was initially adjusted to maintain $\mathrm{PaCO}_{2}$ between $30-40$ torr; no changes were made in minute ventilation once the protocol began. Blood gas tensions were measured within $5 \mathrm{~min}$ of sampling and the results were corrected to the animal's temperature.

Preparation of bacteria. Group B $\beta$-hemolytic streptococci (type III) were inoculated into Todd Hewitt broth and incubated at $32^{\circ} \mathrm{C}$ for $18 \mathrm{~h}$ prior to each animal experiment. The broth culture was centrifuged at $4 \times g$ at $3^{\circ} \mathrm{C}$ for $30 \mathrm{~min}$. The bacterial pellet was resuspended in $10 \mathrm{ml}$ phosphate-buffered saline. Bacterial concentration of the resuspended solution was determined by measurement of the optical density with comparison to a previously determined plot of bacterial colony forming units to optical density.

Assessment of shunt and ventilation perfusion matching. The multiple inert gas elimination technique (14) was employed to determine pulmonary ventilation-perfusion relationships. This technique employs a continuous intravenous infusion of six inert gases of widely varying solubility in blood. Each exhibits a linear relationship between partial pressure and concentration in blood. The retention $(\mathrm{R}=$ arterial/mixed venous concentration), excretion $(E=$ mixed expired/mixed venous concentration), and solubility of each of the six gases are measured at each sampling interval. Retention of a gas of very low solubility, such as sulfur hexafluoride, provides a sensitive indicator of shunt as insoluble gases in mixed venous blood are largely eliminated into alveolar gas as the blood passes through the lungs. Therefore very small shunts are easily detected with the use of this insoluble gas (15).

A previously reported modification of the inert gas technique for small animals was used in this experiment (9). A dilute solution of the six inert gases (sulfur hexafluoride, ethane, cyclopropane, halothane, diethyl ether, acetone), dissolved in 5\% dextrose and normal saline, was infused intravenously at a rate of $6 \mathrm{ml} / \mathrm{kg} / \mathrm{h}$. Five-milliliter samples of arterial and mixed venous blood and 20-ml samples of mixed expired gas were obtained simultaneously for assessment of inert gas concentrations at predetermined times in the experiment (see below).

Blood samples were drawn into heparinized $30 \mathrm{ml}$ preweighed, glass syringes with matched barrels which were reweighed to determine the volume of blood in each sample. The blood samples were then tonometered with $15 \mathrm{ml}$ of nitrogen gas for $45 \mathrm{~min}$ in a water bath. Samples of mixed expired gas were withdrawn into a preheated gas-tight syringe and analyzed within $1 \mathrm{~h}$ of collection. Inert gas concentrations were measured in the carrier gas of the blood samples and in the expired gas sample with gas chromatography (Beckman GC 72-5). Concentrations of sulfur hexafluoride were measured by an electron capture detector operating in parallel with the gas chromatograph. The inert gas concentrations in the blood samples and solubility of the gas in blood were then calculated (16). Retention and excretion versus solubility curves were drawn and a computer program using a least squares technique for best fitting of the data provided the value of fractional $\dot{Q}_{p}$ perfusing 50 theoretical lung compartments, each with a unique $\dot{V}_{\mathrm{A}} / \mathrm{Q}$ ratio $(14,17)$.

Ventilation-perfusion matching in the lung was assessed using the SD $\dot{Q}_{p}$ as an indicator of the closeness of matching of ventilation and perfusion $(18,19)$. A narrow or small SD $\dot{Q}_{p}$ indicates blood flow tightly constrained to well ventilated areas; an enlarged SD $\dot{Q}_{p}$ implies substantial pulmonary blood flow to lung regions with a wider distribution of $\dot{V}_{\mathrm{A}} / \mathrm{Q}$; thus perfusion is less tightly matched to alveolar ventilation. For analysis of $\mathrm{SD}$ $\dot{\mathrm{Q}}_{\mathrm{p}}, \dot{\mathrm{Q}}_{\mathrm{p}}$ is the fraction of $\dot{\mathrm{Q}}_{\mathrm{t}}$ where $\dot{\mathrm{Q}}_{\mathrm{p}}=\dot{\mathrm{Q}}_{\mathrm{t}}-\dot{\mathrm{Q}}_{\mathrm{s}}$ with $\mathrm{Q}_{\mathrm{t}}$ equal to total pulmonary blood flow, and $\dot{Q}_{s}$ equal to flow to areas of zero ventilation.

Study protocol. An intravenous infusion of group B streptococci (total dose of $2 \times 10^{9}$ colony forming units per kilogram) was infused over $30 \mathrm{~min}$. Hemodynamic measurements, arterial blood gas tensions, $\mathrm{pH}$, and inert gas samples were obtained before, $20 \mathrm{~min}$ after the onset of the infusion, and at $20 \mathrm{~min}, 1$ $\mathrm{h}$, and $2 \mathrm{~h}$ after discontinuing the bacterial infusion.

Statistics. Statistical analysis was performed using analysis of variance and Newman-Keuls' multiple-range test (20). The level of significance was $p<0.05$. Data are presented as mean \pm 1 $\mathrm{SD}$.

\section{RESULTS}

Mean pulmonary arterial pressure increased immediately upon initiation of the infusion of GBS and reached a maximum value within 5 min after the onset of the infusion. Mean Ppa increased from a baseline value of $14.2 \pm 2.8$ to $37.6 \pm 6.7$ torr, $(p<0.01)$ after infusing bacteria for $20 \mathrm{~min}$ (Fig. 1). Mean Ppa then returned toward preinfusion values after discontinuing the infusion.

$\dot{Q}_{p}$ fell to $65 \%$ of baseline values 20 min after beginning the infusion $(p<0.02)$ (Fig. 1). This occurred uniformly in every animal. Heart rate was increased $20 \mathrm{~min}$ after beginning the
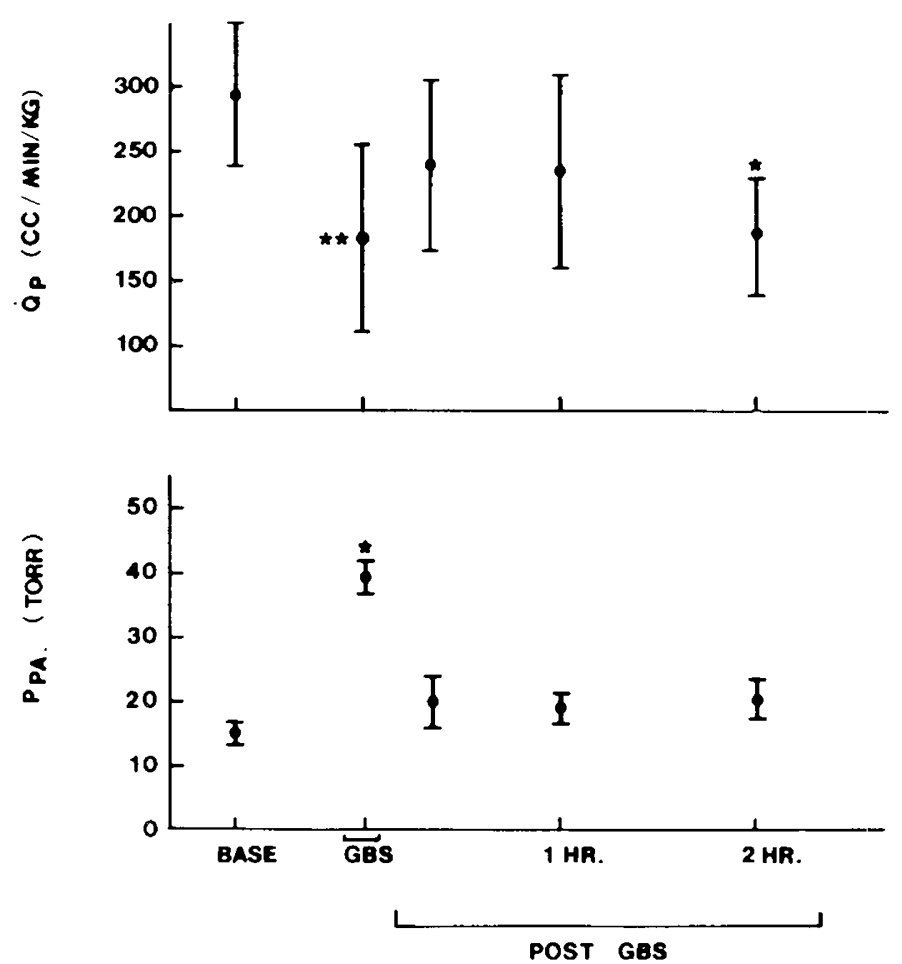

Fig. 1. $\dot{Q}_{p}$ and Ppa are plotted. Base means baseline conditions. The short bar above GBS on the abscissa indicates the 30-min infusion time of the group B streptococci. Post-GBS refers to the 2-h period following the end of the bacterial infusion. ${ }^{* *} p<0.02$ compared to baseline. ${ }^{*} p$ $<0.05$ compared to bascline. 
Table 1. Heart rate and calculated stroke volume data (mean \pm I SD)

\begin{tabular}{|c|c|c|c|c|c|}
\hline Condition & Baseline & $\begin{array}{l}20 \mathrm{Min} \\
\text { into infusion }\end{array}$ & $\begin{array}{c}20 \text { Min } \\
\text { after infusion }\end{array}$ & $\begin{array}{l}1 \mathrm{H} \text { after } \\
\text { infusion }\end{array}$ & $\begin{array}{l}2 \mathrm{H} \text { after } \\
\text { infusion }\end{array}$ \\
\hline Heart rate $(\mathrm{bpm})$ & $172 \pm 14$ & $198 \pm 45^{*}$ & $193 \pm 38$ & $211 \pm 39^{*}$ & $256 \pm 47 \dagger$ \\
\hline Calculated stroke volume $(\mathrm{ml})$ & $5.9 \pm 1.1$ & $3.1 \pm 1.0 \dagger$ & $4.2 \pm 0.9$ & $3.8 \pm 1.2$ & $2.6 \pm 0.8^{*}$ \\
\hline
\end{tabular}

$* p<0.05$ versus baseline.

$\dagger p<0.005$ versus baseline.

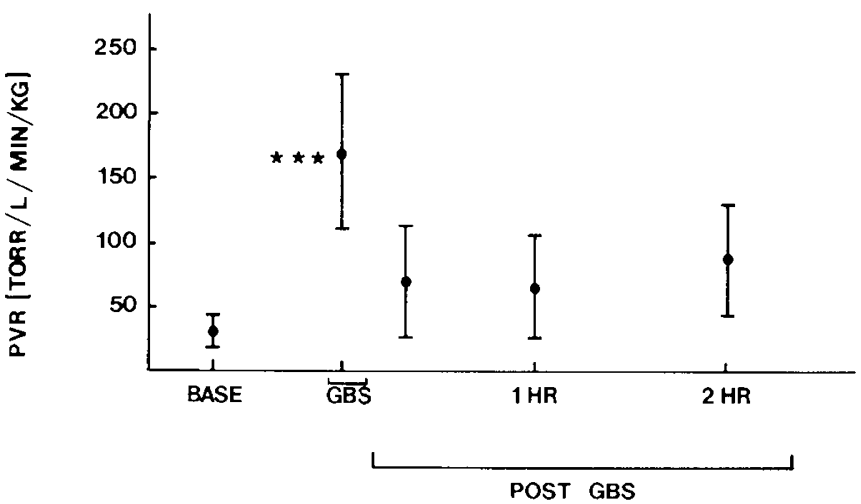

Fig. 2. PVR is plotted against experimental conditions (see legend of Fig. 1 for detail). ${ }^{* * *} p<0.0001$ compared to baseline.
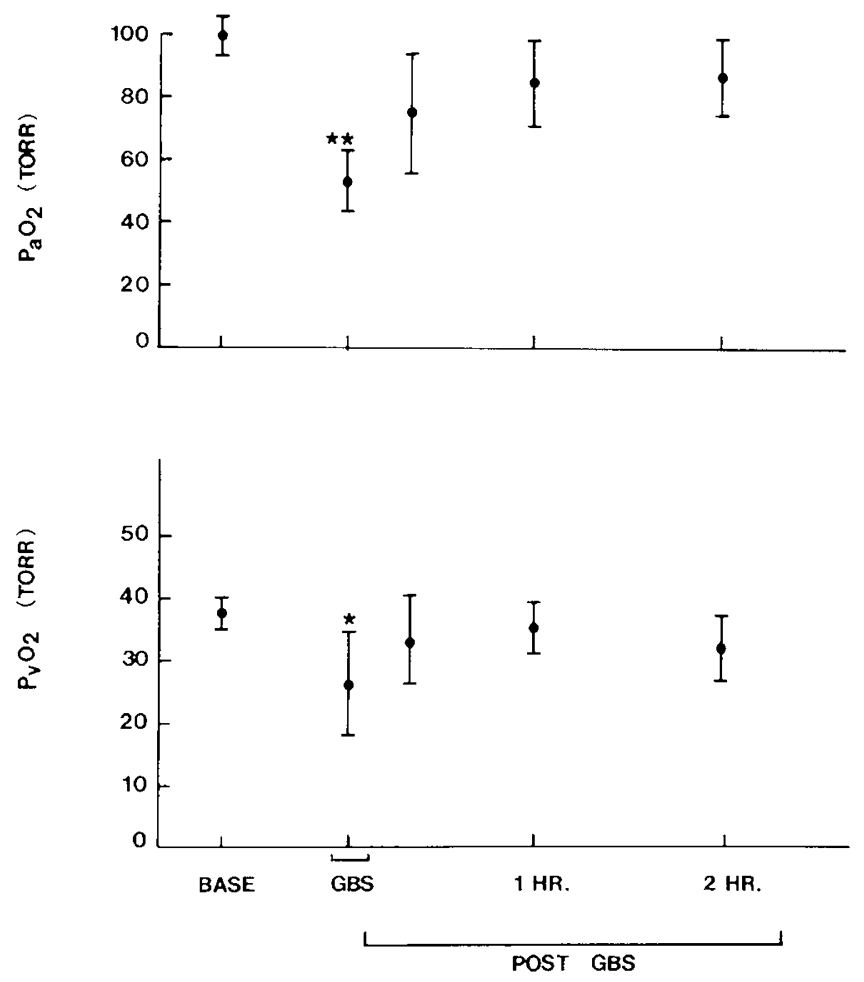

Fig. 3. Arterial $\mathrm{PO}_{2}$ and mixed venous $\mathrm{PO}_{2}$ are plotted against the experimental conditions (see legend of Fig. I for details). ${ }^{* *} p<0.02$ compared to baseline. ${ }^{*} p<0.05$ compared to baseline.

infusion and at $1 \mathrm{~h}$ and $2 \mathrm{~h}$ after discontinuing the infusion compared to the baseline heart rates (Table 1). Calculated stroke volume was significantly reduced during the infusion and at $2 \mathrm{~h}$ after ending the infusion (Table 1).

PVR was increased by $545 \%$ above baseline values during the infusion $(p<0.001)$, but also returned toward baseline after the infusion was stopped (Fig. 2). Pulmonary capillary wedge pressure was significantly increased during the GBS infusion compared to baseline $(9.7 \pm 2.6$ versus $5.1 \pm 2.1$ torr, $p<0.01)$ but returned to baseline values after the infusion. The mean systemic arterial pressure of $93 \pm 8$ torr at baseline did not vary significantly at any sampling time.
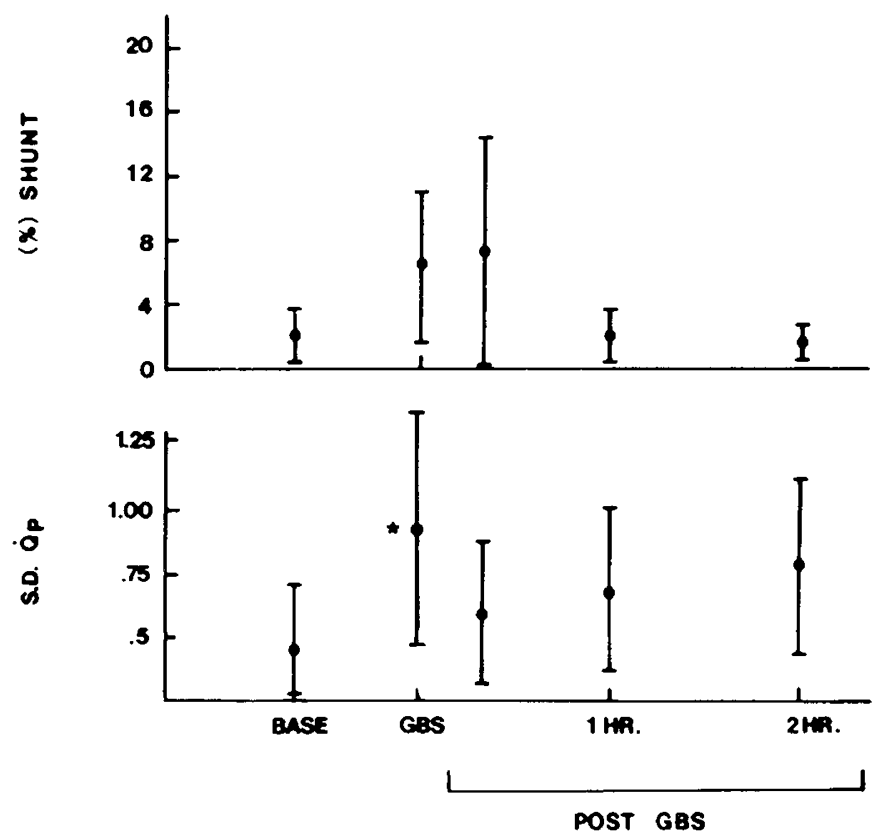

Fig. 4. Intrapulmonary shunt and SD $\dot{Q}_{p}$ are plotted against experimental conditions. There was no significant change in percentage shunt at any experimental time. ${ }^{*} p<0.05$ compared to baseline.

Arterial $\mathrm{PO}_{2}$ decreased by an average of 40 torr $(p<0.02)$ and mixed venous $\mathrm{PO}_{2}$ decreased by 11 torr $(p<0.05) 20$ min into the infusion of the bacteria (Fig. 3). Both returned to baseline following the bacterial infusion. Arterial $\mathrm{pH}$ and $\mathrm{PCO}_{2}$ did not change significantly during the study from baseline values of $7.47 \pm 0.04$ and $36 \pm 4$ torr, respectively.

Mean shunt fraction was not significantly different from the baseline value at any time (Fig. 4). An increase in shunt fraction from 2 to $9 \%$ did develop in two of the 10 animals during the infusion and in one animal $20 \mathrm{~min}$ after the infusion was discontinued. In the remainder, the maximum shunt was $<6 \%$.

The SD $\dot{Q}_{\mathrm{p}}$, the index of ventilation-perfusion heterogeneity, was significantly increased only during the bacterial infusion $(p$ $<0.05$ ), and then returned toward preinfusion values following discontinuation of the infusion (Fig. 4). Figure 5 depicts a typical $\dot{\mathrm{V}}_{\mathrm{A}} / \dot{\mathrm{Q}}$ pattern before the bacterial infusion and $20 \mathrm{~min}$ into the infusion, illustrating the change in the pattern of $\dot{Q}_{p}$ distribution with an overall broadening of the perfusion pattern.

Mean and peak airway pressures were $5 \pm 2$ and $14 \pm 3 \mathrm{~cm}$ $\mathrm{H}_{2} \mathrm{O}$, respectively, at baseline. Neither changed significantly at any experimental time during the experiment.

Blood cultures were obtained prior to the bacterial infusion and were sterile in all cases. Quantitative blood cultures obtained immediately following the bacterial infusion, and $2 \mathrm{~h}$ after the end of the infusion, grew $5 \times 10^{4}$ and $1 \times 10^{2}$ colony forming units per milliliter, respectively.

\section{DISCUSSION}

Neonatal piglets in this study demonstrated the expected rapid onset and large increase in pulmonary arterial pressure and development of arterial hypoxemia during a 30-min infusion of GBS. Additionally, they exhibited a decrease in $\dot{Q}_{p}$ and mixed 

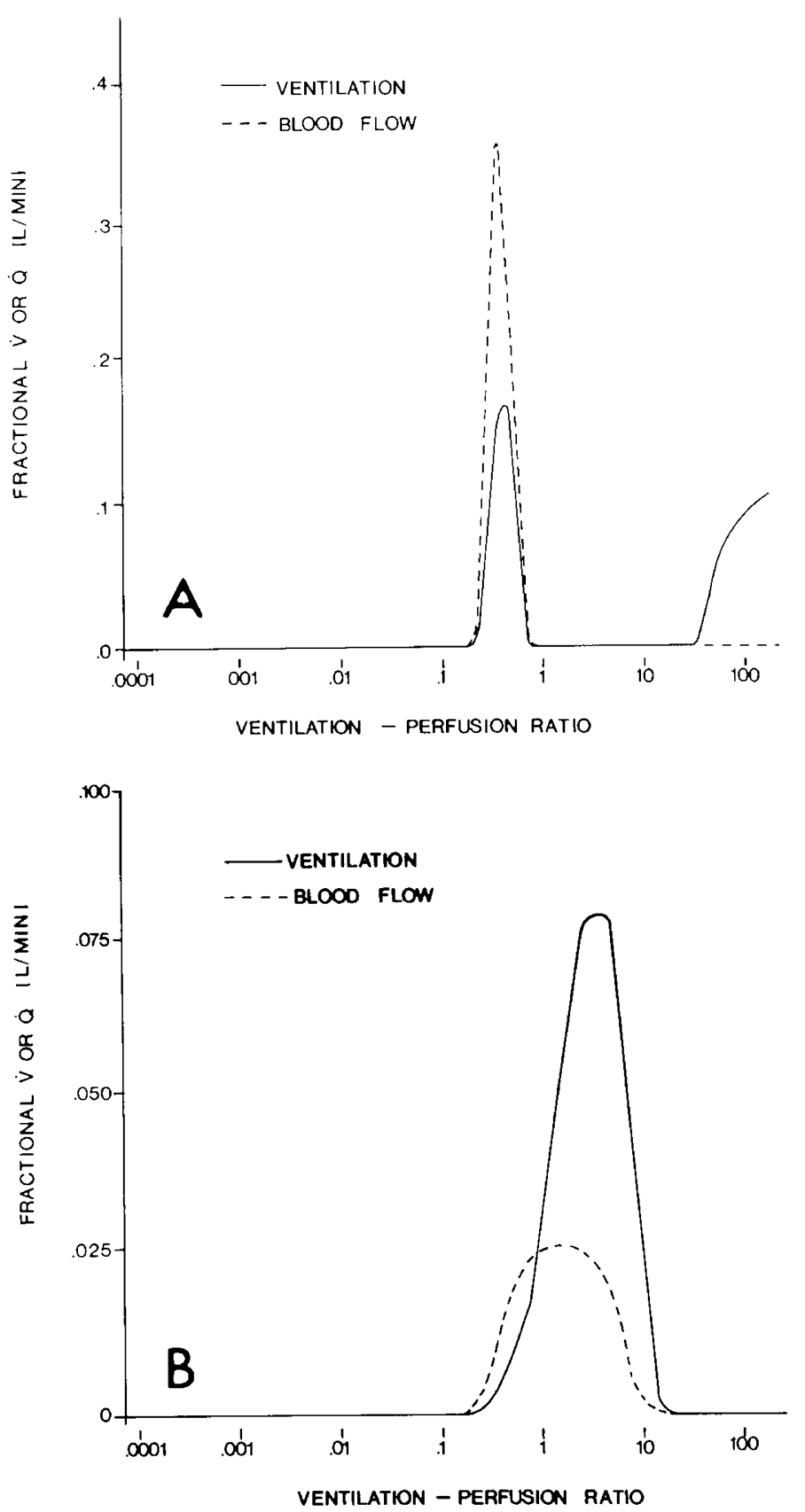

Fig. 5. A representative example of the pattern of $\dot{V}_{\mathrm{A}} / \dot{\mathrm{Q}}$ distribution during baseline conditions $(A)$ and after $20 \mathrm{~min}$ of bacterial infusion $(B)$. Plotted on the abscissa is $\mathrm{V}_{\mathrm{A}} / \mathrm{Q}$ ratio (log scale); plotted on the ordinate is fractional $\dot{V}_{A}$ or $\dot{Q}$. There was no shunt in either situation. SD $\dot{Q}_{p}$ increased from 0.36 to 0.87 . This can be appreciated by the broadening of the $\dot{Q}_{p}$ pattern.

venous $\mathrm{PO}_{2}$. They also demonstrated a transient increase in the degree of ventilation-perfusion mismatching. Although there was a trend toward an increase in shunt, no statistically significant increase was detected. A larger mean increase in shunt might have occurred if the PVR of vasculature associated with ventilated lung areas had increased compared to the initially higher PVR in the vasculature associated with poorly ventilated areas. These data partially refute the hypothesis that hypoxemia in this model is due exclusively to increased shunt. Rather, hypoxemia results from mismatching of pulmonary perfusion to ventilated lung units, and from a substantial decline in cardiac output and in mixed venous $\mathrm{PO}_{2}$. With unchanging tissue oxygen extraction, a decreased cardiac output results in a lower $\mathrm{P}_{\mathrm{v}} \mathrm{O}_{2}$. As blood with this lower $\mathrm{P}_{\mathrm{v}} \mathrm{O}_{2}$ perfuses unventilated or very poorly ventilated lung units, less than complete hemoglobin saturation occurs and the resultant pulmonary venous and systemic arterial $\mathrm{PO}_{2}$ will be depressed assuming some degree of venous admixture is already present (21).

The present results imply diminished capacity for maintenance of ventilation-perfusion relationships in newborns when an abrupt increase in Ppa and fall in $\dot{\mathrm{Q}}_{\mathrm{p}}$ develop. The $2 \%$ shunt found with baseline conditions (Fig. 4) was less than that found in 1day-old lambs (9). These differences suggest improved matching of ventilation with pulmonary perfusion during the first $2 \mathrm{wk}$ of life.

The cause of the transient alteration in $\dot{V}_{\mathrm{A}} / \mathrm{Q}$ matching is not clear. Had pulmonary edema developed as part of the pulmonary arterial hypertension, a sustained increase in low $\mathrm{V}_{\mathrm{A}} / \dot{\mathrm{Q}}$ areas might have been expected, as fluid in small airways should raise resistance to airflow and diminish ventilation to gas exchange areas distal in those airways. However, the transient nature and reversibility of the $\dot{V}_{\mathrm{A}} / \dot{Q}$ mismatching and improvement in arterial $\mathrm{PO}_{2}$ argues against an increase in extravascular lung water. Lava et al. (22) have shown in adult pigs that elevated Ppa to greater than twice normal by continuous bacterial infusion promotes extravascular lung water formation only after several hours of continuous bacterial infusion. Once developed, the increased extravascular lung water did not resolve within 12 to $24 \mathrm{~h}$. Edema formation should diminish lung compliance, which in our anesthetized, paralyzed model, should result in increased airway pressure to deliver the same fixed tidal volume. No change in airway pressure was noted at any time during the experiment. However, it is possible that the degree of bronchoconstriction in some small airways was increased by the GBS infusion and that this effect could be masked by the relatively large tidal volumes and slow ventilatory rates used in the experiment. Use of the inert gas technique does not allow anatomic correlations with the shunt and low $\dot{V}_{\mathrm{A}} / \mathrm{Q}$ areas. We speculate that perfusion redistribution rather than ventilation redistribution produced the $\dot{\mathrm{V}}_{\mathrm{A}} / \dot{\mathrm{Q}}$ effect noted. This transient change in $\dot{\mathrm{V}}_{\mathrm{A}} / \dot{\mathrm{Q}}$ matching appeared to be reversing while some degree of pulmonary arterial hypertension persisted (Figs. 1 and 4).

The multiple inert gas elimination technique allows serial assessment of pulmonary gas exchange, providing data not easily obtained in other ways. Shunt measurement normally requires the use of $100 \% \mathrm{O}_{2}$ breathing, which may significantly alter the underlying lung conditions resulting in overestimate of shunt, especially in newborns (23). Use of tracer inert gases obivates the need for $100 \% \mathrm{O}_{2}$ breathing to differentiate shunt from venous admixture. The SD $\mathrm{Q}_{\mathrm{p}}$ was used as the index of $\dot{\mathrm{V}}_{\mathrm{A}} / \mathrm{Q}$ mismatching since it reflects the fractional distribution of $\mathrm{Q}_{\mathrm{p}}$ to lung areas with different $\dot{V}_{\mathrm{A}} / \mathrm{Q}$ ratios. The index should be sensitive to increases in perfusion to low $\dot{V}_{\mathrm{A}} / \dot{Q}$ areas (18). Lung regions with $\dot{\mathrm{V}}_{\mathrm{A}} / \mathrm{Q}<1$ are those most likely to contribute to development of hypoxemia (8). Therefore, changes in $\mathrm{SD} \dot{\mathrm{Q}}_{\mathrm{p}}$ should reflect changes in the magnitude of low $\mathrm{V}_{\mathrm{A}} / \mathrm{Q}$ areas, which contribute to the development of hypoxemia.

Intrapulmonary shunt did not increase significantly for the group of animals as a whole. In three animals shunt increased from 2 to $9 \%$ with GBS infusion, and in three animals there was a slight decrease in shunt. The measured inert gas shunt was intrapulmonary, with no contribution from a potential right to left shunt via the ductus arteriosus since the mixed venous sample used to calculate inert gas shunt was obtained distal to the point of attachment of the ductus arteriosus to the pulmonary artery and the arterial sample was preductal. Furthermore, during the increase in Ppa, the peak pulmonary arterial systolic pressure was always less than the sytemic arterial diastolic pressure. Based on this pressure differential, it is unlikely that there was any significant ductal contribution to shunt fraction, or any right to left flow via the foramen ovale. Ductal flow during room air breathing in pigs has been shown to become minimal by $48 \mathrm{~h}$ (24). The piglets in the present study were all at least 10 days old.

The abrupt fall in $\dot{Q}_{p}$ associated with onset of the bacterial infusion is not easily explained. Reduction in $\dot{Q}_{p}$ does not occur 
in the adult sheep undergoing GBS infusion $(4,6)$, but does occur in the young piglet (7). Because heart rate increased with the decrease in $\dot{Q}_{\mathrm{p}}$, there was a fall in stroke volume (Table 1). One reason for this fall would be a decrease in cardiac contractility, assuming no change in preload or afterload conditions. However, the decrease in cardiac output with maintenance of an unchanged systemic blood pressure suggests that afterload was increased. Therefore, these data neither substantiate nor refute a role for intrinsic myocardial depression in sepsis or endotoxemia, previously demonstrated to occur acutely with Escherichia coli endotoxin infusion in dogs (25). The increase in pulmonary capillary wedge pressure found in the present experiments might reflect a specific effect on pulmonary venous constriction, but isolated lobar preparations might be needed to confirm this possibility.

The present work confirms the previous findings of Runkle $e t$ al. (7) and extends their work by determining the mechanism of hypoxemia. However, the two experimental conditions were not exactly analogous. Runkle et al. (7) used a continuous infusion of approximately $7 \times 10^{9}$ colony forming units per kilogram per hour of GBS. This dose is 5-fold higher than the dose we used and was continued for a maximum of a 6-h experimental time period. The rise in mean pulmonary arterial pressure (15 to 39 torr) and the percentage fall in $\dot{Q}_{p}$ (to approximately $60 \%$ of baseline level) (data extracted from Reference 7) are in close agreement with our findings. In contrast, Rojas et al. (6) demonstrated a similar rise in pulmonary arterial pressure in adult sheep (22 to 39 torr) with a bolus infusion of GBS toxin, but a smaller decline in arterial $\mathrm{PO}_{2}$ and in $\dot{\mathrm{Q}}_{\mathrm{p}}$. No data in the work by Runkle et al. (7) or by Rojas et al. (6) describe the relationship of ventilation and pulmonary perfusion during GBS infusion. The animals studied by Rojas et al. (6) were awake and not anesthetized compared to anesthetized animals in the present study and that of Runkle et al. (7).

In summary, we have provided new information demonstrating a transient diminished capacity for maintenance of ventilation-perfusion matching in a neonatal animal during an acute decline in $\dot{Q}_{p}$ and increase in Ppa. This model is not exactly analogous to the human situation in which sepsis occurs at or within hours of birth. Nonetheless, further studies with this model of GBS sepsis should help clarify the relative importance of vasoactive substances, including prostaglandin metabolites (7, 26,27 ), in the cardiac and pulmonary gas exchange abnormalities exhibited, and in the subsequent return toward baseline conditions.

Acknowledgments. The authors gratefully acknowledge the technical assistance of Richard Tuck, and the secretarial assistance of Carleen Atwood and Margaret Pratt. We also acknowledge helpful suggestions with design and performance of the experiment from T. A. Standaert, Ph.D., and C. B. Wilson, M.D.

\section{REFERENCES}

1. Baker CJ 1979 Group B streptococcal infections in neonates. Pediatr Rev 1:515
2. Franciosi RA, Knostmen JD, Zimmermen RA 1973 Group B streptococcal neonatal and infant infections. J Pediatr 82:707-12

3. Howard GB, McCracken GH Jr 1974 The spectrum of group B streptococcal infections in infancy. Am J Dis Child 128:815-819

4. Rojas J, Green RS, Hellerqvist CG, Olegard R, Brigham KL, Stahlman MT 1981 Studies on group $\beta$-hemolytic streptococcus. II: effects on pulmonary hemodynamics and vascular permeability in unanesthetized sheep. Pediatr Res 15:899-904

5. Hellerqvist CG, Rojas J, Green RS, Sell S, Sundell H, Stahlman MT 1981 Studies on group Beta-hemolytic streptococcus. I isolation and partial characterization of an extracellular toxin. Pediat Res 15:892-898

6. Rojas J, Larsson LE, Hellerqvist CG, Brigham KL, Gray ME Stahlman MT 1983 Pulmonary hemodynamic and ultrastructural changes associated with group B streptococcal toxemia in adult sheep and newborn lambs. Pediatr Res 17:1002-1008

7. Runkle B, Goldberg RN, Streitfeld MM, Clark MR, Buron E, Stetzer ES, Bancalari E 1984 Cardiovascular changes in group B streptococcal sepsis in the piglet: response to indomethacin and relationship to prostacyclin and thromboxane $\mathrm{A}_{2}$. Pediatr Res 18:874-878

8. West JB 1977 Ventilation-perfusion relationships. Am Rev Respir Dis 116:919-929

9. Truog WE, Lyrene RK, Standaert TA, Murphy J, Woodrum DE 1982 Effects of PEEP and tolazoline infusion on respiratory and inert gas exchange in epxerimental meconium aspiration. J Pediatr 100:284-289

10. Lock JE, Olley PM, Coceani F 1981 Enhanced B adrenergic receptor responsiveness in hypoxic neonatal pulmonary circulation. Am J Physio 240: $\mathrm{H} 697-702$

11. Truog WE, Standaert TA 1978 Non-rebreathing valve for spontaneously breathing or mechanically ventilated animals. J Appl Physiol 44:974-976

12. Godal A, Belenky D, Standaert TA, Woodrum DE. Hodson WA 1976 Application of the hot wire anemometer to respiratory measurements in small animals. J Appl Physiol 40:275-278

13. Kuipers J, Sidi D. Heymann M, Rudolph A 1982 Comparison of methods of measuring cardiac output in newborn lambs. Pediatr Res 16:594-597

14. Wagner PD, Saltzman HA. West JB 1974 Measurement of continuous distribution of ventilation-perfusion ratios theory. $\mathbf{J}$ Appl Physiol 36:588-599

15. Hlastala MP. Colley PS. Cheney FW 1975 Pulmonary shunt: a comparison between oxygen and inert gas methods. J Appl Physiol 39:1048-1052

16. Wagner PD, Neuman PF, Laravuso R 1974 Simultaneous measurement of 8 foreign gases in blood by gas chromatography. J Appl Physiol 36:600-606

17. Evans JW. Wagner PD 1977 Limits on $\dot{V}_{A} / \dot{Q}$ distributions from analysis of experimental inert gas elimination. J Appl Physiol 42:889-898

18. Fortune JB, Mazzone RW, Wagner PD 1983 Ventilation-perfusion relationships during hemorrhagic hypotension and reinfusion in the dog. J Appl Physiol 54:1071-1082

19. Robinson NB. Chi EY. Robertson HT 1983 Ventilation-perfusion relationships after hemorrhage and resuscitation: an inert gas analysis. J Appl Physiol 54:1131-1140

20. Zar JA 1983 Multiple comparisons. In: Biostatistical Analysis. Prentice-Hall Inc., Englewood Cliffs, NJ, pp 151-155

21. Dantzker DR 1983 Influence of cardiovascular function on gas exchange. Clin Chest Med 4:149 -159

22. Lava JS, Rice CL, Levine HA, Moss GS 1982 Extravascular lung water as a function of the magnitude of pulmonary artery pressure in the septic pig. $J$ Surg Res 32:440-448

23. Parks CR, Alden ER, Woodrum DE, Standaert TA, Hodson WA 1974 Gas exchange in the immature lung II: methods of estimation and maturity. $\mathrm{J}$ Appl Physiol 36:108-115

24. Rowe RD, Sinclair JD, Kerr AR, Gage PW 1964 Duct flow and mitral regurgitation during changes of oxygenation in newborn swine. J Appl Physiol 19:1157-1162

25. Guntheroth WC. Jacky JP, Kawabori I, Stevenson JG, Moreno AH 1982 Left ventricular performance in endotoxin shock in dogs. Am $\mathrm{J}$ Physiol 242:H172-176

26. Rojas J, Larsson LE, Ogletree ML, Brigham KL, Stahlman MT 1983 Effects of cyclooxygenase inhibition on the response to group B streptococcal toxin in sheep. Pediatr Res 17:107-110

27. Short BL, Miller MK. Fletcher JR 1982 Improved survival in the suckling rat model of group B streptococcal sepsis after treatment with nonsteroidal antiinflammatory drugs. Pediatrics 70:343-347 